\title{
EFFECT OF GENOTYPE, SEED DEVELOPMENT STAGES, AND PROCESSING TREATMENTS ON BOWMAN-BIRK INHIBITOR IN SOYBEAN AND ITS LEVEL IN COMMERCIAL SOY PRODUCTS
}

\author{
P. Mittal, V. KumaR* and A. Rani \\ ICAR-Indian Institute of Soybean Research, Khandwa Road, Indore, 452001. India
}

(Received: 24 March 2020; accepted: 21 April 2020)

\begin{abstract}
Bowman-Birk inhibitor (BBI) is a protease inhibitor that affects protein digestibility; however, it is increasingly being recognised as anutraceutical and cosmeceutical molecule. In the present study, BBI concentration during soybean seed development, its loss during processing treatments, and the level in commercial soy products were determined. Significant differences for BBI concentration were observed across the genotypes and seed development stages. Genotype $\times$ seed development stage interaction was also found to be significant $(\mathrm{P}<0.05)$ for $\mathrm{BBI}$ concentration. Boiling, autoclaving, microwave irradiation, and sprouting resulted in significant $(\mathrm{P}<0.05)$ loss of BBI. Minimum loss was observed in sprouting, while autoclaving for 5 min completely deactivated BBI. Microwave irradiation of the soaked seeds resulted in higher BBI loss than of dry seeds. Among the commercial soy products, BBI concentration was high in soy flour brands, minuscule in ready-to-cook miso soup and undetectable in extruded soy products and roasted soy nuts.

Keywords: Bowman-Birk inhibitor, soybean, reproductive stage, processing, commercial products
\end{abstract}

Being the potential contributor of protein in vegetarian/vegan diet, soy products are gaining the attention of consumers across the globe. Beside minerals, vitamins, omega- 3 fatty acids, and fibre, soybean is a rich source of biomolecules, namely isoflavones, tocopherols, and lecithin, which have been demonstrated to reduce the risk of onset of several killer diseases (Kumar et al., 2010; Messina, 2016). These active ingredients of nutraceutical importance are commercially available in several countries. One of the protease inhibitors present in soybean, namely Bowman-Birk inhibitor, a $8 \mathrm{kDa}$ polypeptide comprising of 71 amino acids, which affects the digestibility of proteins, is even increasingly being recognised as an anticancer and cosmeceutical molecule. In 1992, the Food and Drug Administration gave soybean BBI concentrate (BBIC) the status of Investigational New Drug. A plethora of studies suggesting the anticancer activity of BBI in both in vitro and in vivo models are available (KENNEDY, 2005; CLEMENTE et al., 2010). This biomolecule was demonstrated for its efficacy against oral leukoplakia (ARMSTRONG et al., 2013), prostatic hyperplasia (Malkowicz et al., 2001), and colorectal cancer (Clemente \& ARQues, 2014). BBI has also been reported to suppress multiple sclerosis and attenuate muscular atrophy (DAI et al., 2011). Further, BBI in soybean is a potential cosmeceutical molecule, known for its role in skin health, weight loss, and prevention of hair loss (LASSO, 2010; SARKAR et al., 2012; KIM et al., 2017). Therefore, the retention of BBI during processing of soy products is desirable in contrast to Kunitz trypsin inhibitor (KTI), which affects protein digestibility and causes pancreatic hypertrophy in its active form and is sought to be completely inactivated in soy products.

* To whom correspondence should be addressed.

E-mail: vineetksahni@yahoo.com 
Several processing methods like heating, extrusion, sprouting, or combinations of these treatments are employed by soy food industry to inactivate KTI (DIA et al., 2012; CHEN et al., 2014). BBI has relatively better thermo-stability than KTI due to the presence of 5 more disulfide linkages in its structure than KTI, however, these inactivation methods result in the collateral loss of BBI. Commercial soy food products undergo different types of processing treatments during manufacturing, which may affect BBI concentration. However, the reports pertaining to genotypic variation and loss of BBI due to processing treatments are scarce (FrIEDMAN et al., 1991). KUMAR and co-workers (2018) investigated BBI concentration in 7 soybean varieties, which exhibited 3.2-fold variation for the trait. Further, in several countries, consumption of green soybean at immature stage, known as edamame, is becoming increasingly popular compared to soy products processed from mature grains. Better acceptability of edamame among masses is attributed to reduced off/beany flavour and negligible flatulence-inducing oligosaccharides content compared to soy products processed from mature soybean grains. Therefore, it is worthwhile to assess BBI concentration at different soybean seed development stages to understand its level at the picking stage of edamame. Reports concerning the concentration of BBI even in the commercial soy products are limited (HERnÁNDEZ-LEDESMA et al., 2009). In the present investigation, 2 soybean varieties of India were assessed for BBI concentration at different reproductive stages to investigate the dynamics of BBI accumulation. Mature seeds of one variety were subjected to boiling, microwave, autoclaving, and sprouting to assess BBI loss due to these processing methods. In several countries, a wide array of soy-based products has appeared in market to meet consumer needs. Different types of these commercially available soy products undergo different processing methods or combination of them, which would impact BBI concentration differently. Besides, different types of soy products, such as soy flour, soy chunks, soy granules, ready-to-cook miso soup, roasted soy nuts, were also analysed for BBI concentration.

\section{Materials and methods}

\subsection{Soy products}

Soy flour, soy chunks, soy granules, roasted soy nuts, and ready-to-cook miso soup were commercial products and purchased from the market.

\subsection{Picking at different growth stages}

Three soybean genotypes, namely NRC127, DS228, and JS97-52, were raised in the field in single row plot of 3 meter length with plant-to-plant and row-to-row distance of 5 and $45 \mathrm{~cm}$, respectively, in triplicate in randomised block design. These 3 genotypes are soybean varieties released for cultivation in India. Green pods of 2 genotypes, namely NRC127 and DS228, were picked at R5, R6, and R7 stage as described by FEHR and co-workers (1971). Fresh tender seeds were shelled from these green pods and recorded for moisture content and 100 green seed fresh weight. A fixed weight of green seeds picked at each of the reproductive stages was taken for BBI estimation and the data were converted on dry weight basis.

\subsection{Processing treatments}

Seeds of soybean variety JS 97-52 were subjected to boiling, autoclaving, microwave irradiation, and sprouting. Dry seeds were boiled in distilled water at $100{ }^{\circ} \mathrm{C}$ for 5,10 , and 15 
min. Autoclaving of soybean seeds was carried out at $121{ }^{\circ} \mathrm{C}$ and 15 psi for $15 \mathrm{~min}$. For microwave treatment, both dry and pre-soaked seeds (immersed in distilled water for $30 \mathrm{~min}$ ) were irradiated in microwave oven (Samsung Model-MC28H5015VB, $0.6 \mathrm{KW}$ power set at $2450 \mathrm{MHz}$ frequency) for 1 and $2 \mathrm{~min}$. For sprouting, soybean seeds were sprouted in germination paper at $28^{\circ} \mathrm{C}$, and the seedlings were drawn for analysis after every $24 \mathrm{~h}$ till 4 days.

\subsection{Extraction and estimation of BBI through ELISA}

Defatted soy flour $(50 \mathrm{mg})$ was suspended in $1 \mathrm{ml}$ of $50 \mathrm{mM}$ Tris buffer $(\mathrm{pH} 8.2)$ and homogenised using Polytron homogeniser (Kinematica, Model PT2100, Switzerland) followed by ultra-sonication (PCI Analytics) for $1 \mathrm{~h}$. The suspension was centrifuged at $20000 \mathrm{~g}$ for $35 \mathrm{~min}$ at $4{ }^{\circ} \mathrm{C}$. The resultant supernatant was diluted 25000 times using phosphate buffer saline. A standard curve $\left(y=0.03 x+0.3146, \mathrm{R}^{2}=0.996\right)$ was generated using varying BBI standard concentration. BBI concentration in samples was quantified using indirect ELISA method as described elsewhere (KUMAR et al. 2018).

\subsection{Statistical analysis}

All steps and assays were performed in triplicate with satisfactory repetition of values. Data presented in Table 1 and 2 are mean \pm standard deviation of 3 independent replicates. All statistical analyses were carried out through $S A S 9.3$ with significance at $\mathrm{P}<0.05$.

\section{Results and discussion}

\subsection{Genotypic and seed development stages differences}

In general, mature soybean seeds are used as raw material for processing different soy products. However, soybean is picked at immature stage, i.e. R5, R6, or between R6-R7 stages for consumption as vegetable. Figure 1 depicts BBI concentration in 2 soybean varieties picked at 3 seed development stages, namely R5, R6, and R7 stages of reproductive phase. These seed development stages, i.e. R5, R6, and R7 in soybean have been defined by FeHR and co-workers (1971). Fresh green seed weight of these 2 genotypes increased as reproductive stage transitioned from R5 to R6 and thereafter from R6 to R7 stage. BBI concentrations in mature seeds of NRC127 and DS228 were found to be 11.4 and $3.7 \mathrm{mg} \mathrm{g}^{-1}$ dry matter, respectively, exhibiting about 4 fold genotypic variation. Further, it may be noted that NRC127 is a KTI free soybean variety released for cultivation in India, and is essentially derived from variety JS97-52, as the former constitutes $96.2 \%$ genome of the latter (AICRPS, 2018). BBI concentration in NRC127 continuously increased as the seed development progressed from R5 to R8 stage. At R5 stage, BBI concentration in NRC127 was $4.83 \mathrm{mg} \mathrm{g}^{-1}$ dry matter, which spiked to $11.4 \mathrm{mg} \mathrm{g}^{-1}$ dry matter at maturity. The variety registered maximum increase of $52.0 \%$ in BBI accumulation between R5 to R6 stages, $21.4 \%$ increase between R6 and R7 stages and 27.9\% increase between R7 and R8 stages. In case of DS228, at R5 stage, BBI concentration was $1.89 \mathrm{mg} \mathrm{g}^{-1}$ dry matter, which at R8 stage increased to 3.7 $\mathrm{mg} \mathrm{g}^{-1}$ dry matter. Like NRC127, DS228 registered about 52\% increase in BBI between R5 and R6 stages, however, both between R6 and R7, and R7 and R8 stages, the percent increase in BBI concentration was about half of NRC127. These results showed that the effects of genotype, seed development stage, and genotype $\times$ seed development stage interaction were 
significant $(\mathrm{P}<0.05)$ on the accumulation of $\mathrm{BBI}$ concentration in soybean. The data showed that soybean at R5 stage may possess half the concentration of BBI at full maturity. To compare our results, we could not come across any previous studies wherein accumulation pattern of BBI during soybean seed development has been reported in the literature.

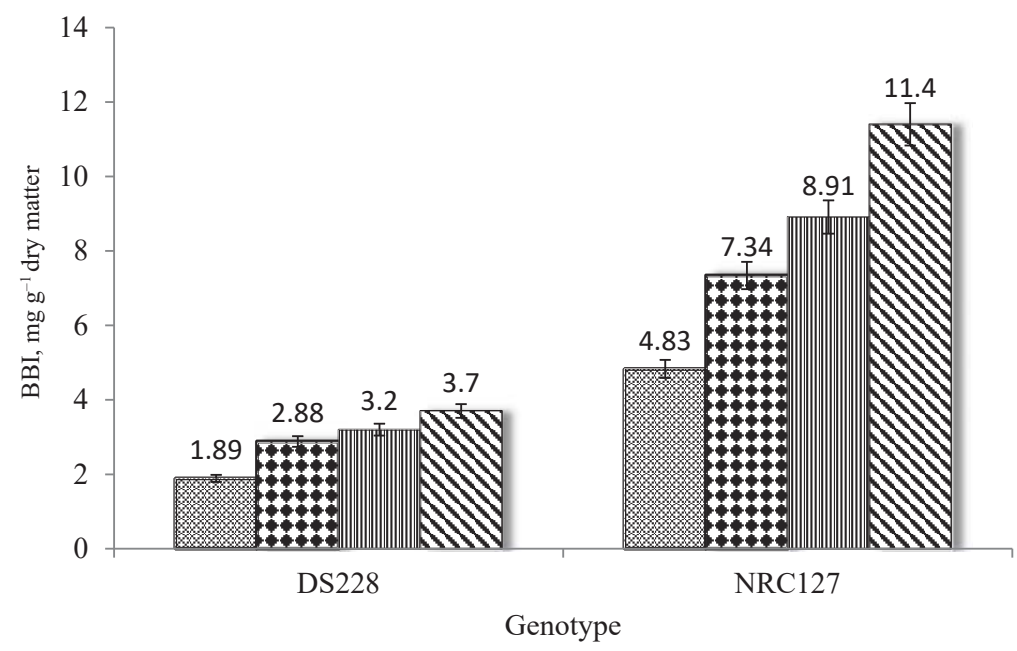

Fig. 1. BBI concentration of soybean genotypes DS228 and NRC127 at different seed development stages (R5, R6, R7, and R8). Numerical value given on the top of the bar corresponds to BBI concentration $\mathrm{mg} \mathrm{g}^{-1}$ dry matter at the particular seed development stage of genotype

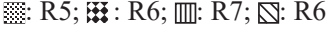

\subsection{Effect of processing treatments}

Variety JS97-52 was chosen for investigating the effect of processing treatment. BBI concentration in the untreated sample of JS97-52 (7.4 $\left.\mathrm{mg} \mathrm{g}^{-1}\right)$ was also found to be much lower than observed in NRC127 (11.4 $\left.\mathrm{mg} \mathrm{g}^{-1}\right)$. The data pertaining to the loss of BBI due to 4 processing treatments, i.e. boiling, autoclaving, microwave irradiation, and sprouting, are presented in Table 1. Boiling of seeds for 5, 10, and 15 min reduced BBI from 7.4 to 3.4, 1.5, and $1.2 \mathrm{mg} \mathrm{g}^{-1}$, thereby causing 52, 79.7, and $83.8 \%$ loss, respectively. The results of our previous study (KUMAR et al., 2019) showed that boiling of soybean seeds for 5 and 10 min caused a loss of KTI, the major protease inhibitor in soybean, to the magnitude of 68.8 (from 11.2 to $3.5 \mathrm{mg} \mathrm{g}^{-1}$ ) and $75.9 \%$ (from 11.2 to $2.7 \mathrm{mg} \mathrm{g}^{-1}$ ), respectively. Autoclaving (at $121^{\circ} \mathrm{C}$ and 15 psi) of soybean seeds for 15 min completely deactivated BBI. Complete inactivation of KTI as a result of autoclaving for $15 \mathrm{~min}$ has also been reported in our previous study (KUMAR et al., 2019). FrIEDMAN and co-workers (1991) investigated the effect of autoclaving of soy flour on BBI content, and reported 78.0 and $98.8 \%$ loss of BBI in soy flour on autoclaving at $121^{\circ} \mathrm{C}$ for 10 and $20 \mathrm{~min}$, respectively, which is comparable to the extent of $\mathrm{BBI}$ loss due to autoclaving for $15 \mathrm{~min}$ in the present study.

With regard to microwave irradiation, this treatment for $1 \mathrm{~min}$ in dry seeds plummeted BBI from 7.4 to $5.4 \mathrm{mg} \mathrm{g}^{-1}$, causing $27 \%$ loss, however, exposure of soaked seed to microwave radiation for the same duration reduced this biomolecule concentration from 7.4 to $0.5 \mathrm{mg} \mathrm{g}^{-1}$, resulting in $93.4 \%$ loss, i.e. about 3 -fold higher loss than in dry seeds. Higher percentage of 
loss for BBI was registered in both dry and soaked seeds with 2 min exposure to microwave irradiation compared to the lesser duration of $1 \mathrm{~min}$, i.e. microwave irradiation induced loss of BBI was proportionate to exposure time, whether the seeds were soaked or dried. Our results also showed that microwave irradiation for $2 \mathrm{~min}$ also caused significantly higher BBI loss in soaked seeds than in dry seeds. Similar observations were reported for KTI reduction due to microwave irradiation in an earlier study (KUMAR et al., 2019), which reported the reduction of the KTI due to microwave irradiation as a function of exposure time and the moisture percent in seed, and the higher reduction observed in soaked compared to dried seeds on microwave irradiation may be because of the higher electric dipole forms due to water molecules in the former case, which may result in intense heat energy transfer to proteins. In literature, the studies demonstrating the effect of microwave irradiation on total trypsin inhibitor activity (TIA) on soybean and other beans are available. SzMIGIELSKI and co-workers (2010) reported 15.0 and $26.84 \%$ reduction in TIA of dry Polish bean flour on exposure to microwave irradiation for 1 and $2 \mathrm{~min}$, respectively.

Table 1. Changes in BBI concentration in soybean due to different processing treatments

\begin{tabular}{lcc}
\hline Treatment & $\begin{array}{c}\text { BBI concentration } \\
\mathrm{mg} \mathrm{g}^{-1} \text { dry matter }\end{array}$ & $\begin{array}{c}\text { Percent reduction } \\
\text { compared to the control }\end{array}$ \\
\hline Control & $7.4 \pm 0.37^{\mathrm{a}}$ & \\
Boiling & $3.4 \pm 0.19^{\mathrm{d}}$ & 54.1 \\
5 min & $1.5 \pm 0.10^{\mathrm{e}}$ & 79.7 \\
10 min & $1.2 \pm 0.10^{\mathrm{e}}$ & 83.8 \\
15 min & n.d. & 100 \\
Autoclaving (15 min) & & \\
Microwave irradiation (dry seeds) & $5.4 \pm 0.18^{\mathrm{c}}$ & 27.0 \\
1 min & $1.2 \pm 0.09^{\mathrm{e}}$ & 83.8 \\
2 min & & \\
Microwave irradiation (pre-soaked seeds) & $0.5 \pm 0.07^{\mathrm{f}}$ & 93.2 \\
1 min & $0.4 \pm 0.03^{\mathrm{f}}$ & 94.6 \\
2 min. & & 0 \\
Sprouting & $7.6 \pm 0.48^{\mathrm{a}}$ & 4.1 \\
1 day & $7.1 \pm 0.45^{\mathrm{a}}$ & 10.8 \\
2 days & $6.6 \pm 0.41^{\mathrm{b}}$ & 16.2 \\
3 days & $6.2 \pm 0.35^{\mathrm{b}}$ & \\
4 days & & \\
\hline
\end{tabular}

Values given are means of triplicate \pm standard deviation and expressed on dry weight basis. Values superscripted with different letters are significantly $(\mathrm{P}<0.05)$ different from each other. n.d.: not detected

The data presented in Table 1 also show that sprouting caused only 10.8 and $16.2 \%$ loss in BBI concentration in soybean on $3^{\text {rd }}$ and $4^{\text {th }}$ day, which is comparable to $13 \%$ loss reported for this molecule after 3 days of sprouting in soybean in an earlier study (DiA et al., 2012). BBI loss occurring after 4 days of sprouting was about one fifth of the reduction $(66.1 \%)$ for KTI concentration reported in our previous study (KumAR et al., 2019). DiA and co-workers 
(2012) investigated the effect of germination on BBI in soybean seeds sprouted for $72 \mathrm{~h}$ (3 days) at $25{ }^{\circ} \mathrm{C}$ and reported non-significant changes in both KTI and BBI due to sprouting. A $10.8 \%$ reduction in $\mathrm{BBI}$ after $72 \mathrm{~h}$ in our results may be attributed to higher temperature at which sprouting was carried out in the present investigation. The decline in BBI due to sprouting may be because of the de novo synthesis of proteases during sprouting as suggested in an earlier study (PAPASTOITSIS \& WiLSON, 1991).

\subsection{Concentration in commercial products}

Table 2 presents BBI concentration in different types of soy products analysed. Soy flour showed very high BBI concentration, which was as high as reported in soybean varieties (Kumar et al., 2018). This shows that no heat treatment has been applied during soy-flour manufacturing of these brands. However, in the rest of the soy-products, such as soy granules, soy chunks, and roasted soy nuts, BBI concentration was non-detectable. Soy granules and soy chunks both are extruded products. ClarKe and WiSEMAN (2007) investigated the effect of extrusion conditions on TIA of full fat soybean, and reported negligible value of $1.6 \mathrm{mg} \mathrm{g}^{-1}$, which could be due to BBI only, as extrusion completely destroys KTI. BBI was not detectable in roasted soybean nuts either. BARAC and StANOJEvic (2005) reported that 2 min of microwave roasting led to about $88 \%$ reduction of total TIA and the residual activity in this study may be attributed to BBI. In the present study, though both modes of roasting and the duration of roasting in roasted soy nuts packets were not mentioned, however, non-detectable values of BBI may be due to exhaustive roasting treatment given to this soy-product rather than microwave roasting applied for only $2 \mathrm{~min}$ in the above mentioned study. Further, minuscule BBI concentration observed in ready-to-cook soy miso soup may be because of the presence of beneficial fungi culture in this product, which release proteases to degrade BBI.

Table 2. BBI concentration in different soy products

\begin{tabular}{lc}
\hline Soy product & BBI mg g product dry weight basis $^{-1}$ \\
\hline Soy flour & $12.4 \pm 0.21$ \\
Ready-to-cook miso soup & 0.003 \\
Soy granules & n.d \\
Soy chunks & n.d. \\
Roasted soy nuts & n.d. \\
\hline
\end{tabular}

Values given are mean of triplicate \pm standard deviation and expressed on dry weight basis. n.d corresponds to nondetectable.

\section{Conclusions}

In the backdrop of recent reports demonstrating the nutraceutical value of BBI, the accumulation pattern of BBI during seed development as a function of genotype was investigated and the loss of BBI due to different processing treatments was assessed. Most of the studies conducted so far concerning the effects of processing treatments focused on total TIA, which does not distinguish KTI from BBI. In the present study, effect of genotype, seed development stage, and genotype $\times$ seed development stage interaction on BBI concentration 
was found to be significant $(\mathrm{P}<0.05)$. Among all the processing treatments employed in the study, sprouting caused minimum BBI loss. Among different types of the commercial soy products investigated, extruded and roasted soy products were found to be devoid of BBI.

The authors acknowledge the support provided by ICAR - Indian Institute of Soybean Research, where this investigation was carried out.

\section{Ethical approval}

This article does not contain any studies involving human participants or animals performed by any of the authors.

\section{Declaration of interest}

The authors report no conflict of interest. The authors alone are responsible for the content and writing of the paper.

\section{References}

Armstrong, W.B., Taylor, T.H., Kennedy, A.R., Melrose, R.J., Messadi, D.V. .. \& Meyskens, F.L. (2013): Bowman-Birk inhibitor concentrate and oral leukoplakia: A random phase IIb trial. Cancer Prev. Res., 6(5), $410-418$.

AICRPS (2018): Proceedings of varietal identification committee meeting held on $15^{\text {th }}$ March during 48th Annual Group meeting of the All India Coordinated Research Project on Soybean (AICRPS) held from March $15^{\text {th }}$ to March $18^{\text {th }}, 2018$ at Raipur. p. 40.

Barac, M.B. \& Stanojevic, S. (2005): The effect of microwave roasting on soybean protein composition and components with trypsin inhibitor activity. Acta Alimentaria, 34, 23-31.

Chen, Y., Xu Z., Zhang, C., Kong, X. \& HuA, Y. (2014): Heat induced inactivation mechanism of Kunitz trypsin inhibitor and Bowman-Birk inhibitor in soymilk processing. Food Chem., 15, 108-116.

Clarke, E. \& Wiseman, J. (2007): Effects of extrusion conditions on trypsin inhibitor activity of full fat soybeans subsequent effects on their nutritional value for young broilers. Brit. Poultry Sci., 48, 703-712.

Clemente,A., Moreno, F.J., Marín-Manzano Mdel, C., Jiménez, E. \& Domoney, C. (2010): The cytotoxic effect of Bowman-Birk isoinhibitors, IBB1 and IBBD2, from soybean (Glycine max) on HT29 human colorectal cancer cells is related to their intrinsic ability to inhibit serine proteases. Mol. Food Nutr. Res., 5(3), 396-405.

Clemente, A. \& Arques, M.C. (2014): Bowman Birk inhibitors from legumes as colorectal chemopreventive agents. World J. Gastroentero., 20(30), 10305-10315.

DaI, H., Ciric, B., Zhang, G.X. \& Rostami, A.M. (2011): Bowman-Birk inhibitor attenuates experimental autoimmune encephalomyelitis by delaying infiltration of inflammatory cell into CNS. Immunol. Res., 51, $145-152$.

Dia, V.P., Gomez, T., Vernaza, G., Berhow, M., Chang, Y.K. \& De Mejia, G.E. (2012): Bowman-Birk and Kunitz protease inhibitors among antinutrients and bio-actives modified by germination and hydrolysis in Brazilian soybean cultivar BRS133. J. Agr. Food Chem., 60, 7886-7894.

Fehr, W.R., Caviness, C.E., Burmood, D.T. \& Pennington. J.S. (1971): Stage of development descriptions for soybeans, Glycine max (L.). Merrill. Crop Sci., 11, 929-931.

Friedman, M., Brandon, D.L., Bates, A.H. \& Hymowitz, T. (1991): Comparison of a commercial soybean cultivar and an isoline lacking the Kunitz trypsin Inhibitor: Composition, nutritional value, and effects of heating. $J$. Agr. Food Chem., 39, 327-335.

Hernández-Ledesma, B., Hsieh, C.C. \& de Lumen, B.O. (2009): Lunasin and Bowman-Birk protease inhibitor (BBI) in US commercial soy foods. Food Chem., 115, 574-580.

Kennedy, A.R. (2005): The status of human trials utilizing Bowman-Birk inhibitor concentrate from soybean. -in: Sugano, M. (Ed.): Soy in health and disease prevention. CRC Press, Taylor \& Francis, pp. 207-223.

Kim, J.E., Kang, Y.G., ParK, J.S., Lim, T.G. \& LeE, K.W. (2017): Review of soybean phytochemicals and their bioactive properties relevant for skin health. J. Food Nutr. Res., 5, 852-858. 
Kumar, V., Rani, A. \& Chauhan, G.S. (2010): Nutritional value of soybean. -in: Singh, G. (Ed.) Soybean: The botany, production and uses. CAB International, pp. 375-403.

Kumar, V., Rani, A., Mittal, P. \& Shuaib, M. (2019): Kunitz trypsin inhibitor in soybean: Contribution to total trypsin inhibitor activity as a function of genotype and fate during processing. J. Food Meas. Charact., 13, $1583-1590$

Kumar, V., Rani, A., ShuaIB, M. \& Mittal, P. (2018): Comparative assessment of trypsin inhibitor vis-à-vis Kunitz trypsin inhibitor and Bowman-Birk inhibitor activities in soybean, Food Anal. Method., 11, 2431-2437.

Lasso, J.N. (2010): The biochemical and functional food properties of Bowman Birk inhibitor. Crit. Rev. Food Sci., 48(1), 94-118.

Malkowicz, S.B., McKenna, W.G., Vaughn, D.J., Wan, X.S., Propert, K.J., .. \& Kennedy, A.R. (2001): Effects of Bowman-Birk inhibitor concentrate in patients with benign prostatic hyperplasia. Prostate, 48(1), 16-18.

Messina, M. (2016): Soy and health update: Evaluation of the clinical and epidemiological literature. Nutrition, 8 , 754.

Papastoitsis, G. \& Wilson, K.A. (1991): Initiation of the degradation of the soybean Kunitz and Bowman-Birk trypsin inhibitors by a cysteine protease. J. Plant Physiol., 96, 1086-1092.

SARKar, R., Chugh, S. \& Garg, V.K. (2012): Newer and upcoming therapies for melasma. Indian J. Dermatol Ve., 78(4), 417-428.

SzMigielski, M., WesolowsKa-JANCZAREK, M. \& SzCZEPANIK, M. (2010): Determination of trypsin activity of microwave heated bean seeds using bromocresole purple index (BCPI). Pol. J. Food Nutr. Sci., 60, 329-333. 